\title{
ĐỔI MỚI ĐÀO TẠO KẾ TOÁN CỦA CÁC NƯỚC TRÊN THẾ GIỚI - BÀI HỌC KINH NGHIẸM CHO VIẸTT NAM
}

\author{
HUỲNH TẤN DŨNG, LÊ THỊ HẢI BÌNH, NGUYỄN QUỐC NHẤT \\ Khoa Kế toán - Kiểm toán, Trường Đại học Công nghiệp thành phố Hồ Chí Minh;
}

huynhtandung_kt@iuh.edu.vn

Tóm tắt. Chuẩn mực kế toán và các hướng dẫn lập báo cáo tài chính của Việt Nam chưa đủ để cung cấp báo cáo tài chính minh bạch, chưa phản ánh đúng tình hình tài chính, kinh doanh của tổ chức, chưa tạo niềm tin cho các nhà đầu tư nước ngoài. Nhận ra những hạn chế này, Việt Nam đang xem xét lộ trình áp dụng chuẩn mực lập báo cáo tài chính quốc tế (IFRS), để xóa bỏ rào cản về tính minh bạch của báo cáo tài chính, thu hút đầu tư nước ngoài, bắt kịp và nhanh chóng hội nhập quốc tế. Để thực hiện được điều này, đòi hỏi sự chung tay góp sức của nhiều vai trò khác nhau, từ các cơ quan ban hành chuẩn mực (Bộ tài chính), từ các chuyên gia kế toán đến các doanh nghiệp, các cá nhân, trong đó phải kể đến vai trò không kém quan trọng của các nhà đào tạo kế toán.

Tăng cường giáo dục, đào tạo kế toán và kiểm toán là một trong những trụ cột của hoạt động xây dựng năng lực thực hiện chuẩn mực và các hướng dẫn lập báo cáo tài chính, nâng cao việc áp dụng các chuẩn mực quốc tế tại các quốc gia khác nhau. Để đảm nhận được vai trò to lớn này, đòi hỏi việc đào tạo kế toán phải có sự đổi mới phù hợp. Với mục đích học hỏi kinh nghiệm đổi mới đào tạo kế toán của các nước trên thế giới, bài báo này tóm tắt việc thay đổi đào tạo kế toán để phù hợp với thực tế áp dụng chuẩn mực IFRS của một số nước trên thế giới, ví dụ cụ thể ở hai nước Trung Quốc và Ukraina, từ đó rút ra các bài học kinh nghiệm cho việc đổi mới đào tạo kế toán tại Việt Nam.

Từ khóa. Áp dụng IFRS, đào tạo kế toán, đổi mới giáo dục, Trung Quốc, Ukraina.

\section{ACCOUNTING EDUCATION INNOVATIONS IN DEVELOPING COUNTRIES - LESSONS FOR VIETNAM}

\begin{abstract}
Vietnamese Accounting Standards and guidelines for preparing financial statements are not sufficient to provide transparent financial reports that accurately reflect the financial and business situation of the organization, not to create confidence in the financial statements for foreign investors. Recognizing these shortcomings, Vietnam is considering a road map for the application of International Financial Reporting Standards (IFRS), to remove barriers to transparency of financial reporting and to attract foreign investment. It helps for catching up and quickly integrating internationally. In order to do this, it requires the participation of various roles from the standard issuer (Ministry of Finance), professional accountants, accountants of each enterprise and many individuals, specially the importance roles of accounting educators.

Strengthening accounting and auditing education is one of the pillars of capacity building for implementing standards and guidelines for making financial reports, enhancing the application of international standards at different countries. In order to take on this great role, accounting educator is required for appropriate innovation. For purpose of learning the innovation experience of accounting education in countries around the world, this paper summarizes the change of accounting education to fit the practice of applying IFRS standards, case study in two countries: China and Ukraine, and give some lessons for the innovation of accounting education in Vietnam.
\end{abstract}

Keywords. Implementation of IFRS, accounting education, innovation education, China, Ukraina.

\section{GIỚI THIỆU}

Báo cáo tài chính chất lượng cao, minh bạch, phản ánh đúng tình hình tài chính và kinh doanh của tổ chức góp phần rất lớn vào sự phát triển khu vực tư nhân và giảm các biến động bằng cách tăng cường cấu 
trúc tài chính quốc gia. Nó giúp làm giảm nguy cơ của các cuộc khủng hoảng thị trường tài chính và tác động kinh tế tiêu cực liên quan, góp phần tăng đầu tư nước ngoài trực tiếp và gián tiếp, đồng thời cũng khuyến khích tiết kiệm. Tuy nhiên, lập báo cáo tài chính theo chuẩn mực Việt Nam (VAS/VFRS) chưa đáp ứng được những điều này, chưa đạt được yêu cầu theo IFRS mà phần lớn các quốc gia đang áp dụng. Tại hội thảo "IFRS - Định hướng và lộ trình áp dụng tại Việt Nam" do Bộ tài chính, phối hợp cùng Hiệp hội kế toán công chứng Anh Quốc (ACCA) tổ chức vào ngày 21/12/2016 tổ chức tại TP.HCM và ngày 23/12/2016 tổ chức tại Hà Nội, Bộ tài chính đã công bố dự thảo lộ trình áp dụng IFRS vào Việt Nam.

- Giai đoạn 2017- 2018: Tổ chức các hoạt động nghiên cứu, hội thảo lấy ý kiến của các chuyên gia, doanh nghiệp, trường đại học về các nội dung dự thảo VAS/VFRS và IFRS. Đào tạo, dịch tài liệu về IFRS. Khảo sát sự sẵn sàng áp dụng IFRS tại các đơn vị có lợi ích công chúng. Đánh giá tác động của việc áp dụng IFRS. Đánh giá các khác biệt về cơ chế tài chính của Việt Nam với IFRS. Lựa chọn một số đơn vị áp dụng thí điểm IFRS.

- Giai đoạn 2018 - 2020: Lựa chọn một số IFRS (khoảng từ 10 - 20 IFRS) đơn giản phù hợp với điều kiện thực tiễn Việt Nam và công bố tuân thủ, áp dụng đối với tất cả các đơn vị có lợi ích công chúng từ năm 2020. Các đơn vị được lựa chọn thí điểm áp dụng từ 2019. Xây dựng hướng dẫn áp dụng IFRS. Tiếp tục tuyên truyền, quảng bá, đào tạo IFRS cho các doanh nghiệp, công ty kiểm toán, trường đại học.

- Giai đoạn 2020 đến 2023: Tiếp tục công bố, tuân thủ thêm một số IFRS (dự kiến nâng số lượng IFRS được tuân thủ lên 30 Chuẩn mực). Khuyến khích các đơn vị không có lợi ích công chúng, nhưng có đủ điều kiện và mong muốn được lập và trình bày báo cáo tài chính theo IFRS. Tiếp tục xây dựng hướng dẫn áp dụng IFRS. Tiếp tục hố trợ các doanh nghiệp trong việc triển khai áp dụng, các trường đại học trong việc đào tạo IFRS.

- Giai đoạn 2023 - 2025: Tuyên bố tuân thủ hoàn toàn IFRS. Tiếp tục hỗ trợ các doanh nghiệp và trường đại học, xây dựng hoàn chỉnh bộ hướng dẫn áp dụng IFRS và sửa đổi, bổ sung, cập nhật hàng năm theo sự thay đồi của quốc tế.

Để đưa được IFRS vào Việt Nam, đòi hỏi Bộ Tài Chính, các trường đào tạo kế toán, các chuyên gia kế toán, các doanh nghiệp và ngay cả các cá nhân phải có lộ trình thay đổi cho phù hợp. Trong đó, nhà đào tạo kế toán phải là người có những bước thay đổi đầu tiên, vì họ quyết định chất lượng những người làm kế toán, kiểm toán trong tương lai. Muốn người làm kế toán, kiểm toán toán vận dụng IFRS một cách thành thạo đòi hỏi chất lượng đào tạo phải tốt, đảm bảo được chất lượng đầu ra. Bài báo này đóng góp một phần các kinh nghiệm về việc đổi mới đào tạo kế toán tại các trường đào tạo kế toán từ các nước trên thế giới, với mục đích tăng cường chất lượng đầu ra của các kế toán viên, kiểm toán viên.

Theo dữ liệu đến tháng 5/2016 trên trang http://www.ifrs.org, đã có hơn 119 quốc gia và vùng lãnh thổ áp dụng IFRS bắt buộc cho các công ty niêm yết. Có thể nói các quốc gia đã áp dụng IFRS từ khá lâu so với Việt Nam, việc đổi mới đào tạo kế toán của các nước cũng đã dần hoàn thiện để phù hợp với nhu cầu thực tế áp dụng IFRS. Do đó, việc học hỏi kinh nghiệm đổi mới đào tạo kế toán của các quốc gia đi trước là điều cần thiết và hữu ích cho việc triển khai và áp dụng IFRS vào Việt Nam.

\section{PHƯƠNG PHÁP NGHIÊN CÚUU}

Thông qua việc tổng hợp kết quả của các nghiên cứu của các tác giả trước đó, bài báo sử dụng phương pháp thống kê phân tích từ đó rút ra các bài học kinh nghiệm và đưa ra một số đề xuất nhằm giúp Việt Nam có những định hướng rõ ràng hơn trong quá trình đổi mới kế toán ở Việt Nam.

\section{THỰC TRẠNG TRIỂN KHAI VÀ ÁP DỤNG IFRS TẠI MỘT SỐ NƯỚC TRÊN THẾ GIỚI}

Sau khi phân tích đặc điểm quốc gia, chính trị, kinh tế, nhóm tác giả chọn hai quốc gia là Trung Quốc và Ukraina. Lý do lựa chọn hai quốc gia này:

- Thứ nhất, Trung Quốc có nền văn hóa phong kiến lâu đời, tư tưởng làm việc theo luật lệ và hướng dẫn chi tiết đã tồn tại rất lâu, ảnh hưởng rất lớn đến việc áp dụng IFRS theo cơ sở nguyên tắc, yêu cầu kế toán viên phải đưa ra các xét đoán nghề nghiệp, điều này rất giống Việt Nam. Đồng thời, Trung Quốc cũng mới mở cửa nền kinh tế giống Việt Nam, thay đổi từ cơ chế tập trung bao cấp sang cơ chế thị trường. Việc chuyển đổi từ chuẩn mực kế toán cũ sang chuẩn mực kế toán theo IFRS đã được Trung Quốc thực hiện từ năm 2006, và đang trên bước đường thuận lợi. 
- Thứ hai, Ukraina là quốc gia thuộc liên bang Xô Viết cũ. Sau khi liên bang Xô Viết tan rã, Ukraina phát triển nền kinh tế theo hướng hội nhập với thế giới. Ukraina đã tiến hành mở cửa và xây dựng nền kinh tế thị trường. Tuy nhiên, đây vẫn là một quốc gia nhỏ, còn gặp khá nhiều khó khăn. Bối cảnh phát triển kinh tế của Uknaina cũng khá tương đồng với Việt Nam. Mặc dù có sự khác biệt về đường lối chính trị, nhưng Việt Nam và Ukraina đều đang phát triển nền kinh tế theo hướng hội nhập, phát triển nền kinh tế thị trường. Hiện nay, chuẩn mực kế toán của Ukraina đã giống $80 \%$ IFRS và quy định thuế thì $98 \%$ đã tuân thủ theo IFRS.

Vì hai quốc gia này có các đặc điểm chính trị, kinh tế giống Việt Nam, và hai quốc gia này đang trong quá trình đổi mới và đều vướng phải những khó khăn cần tháo gỡ trong quá trình đổi mới đào tạo kế toán. Việt Nam với tư cách là nước đổi mới sau sẽ học hỏi được những kinh nghiệm quý báu từ hai quốc gia này để giảm bớt khó khăn và rút ngắn được thời gian triển khai cũng như áp dụng thành công IFRS.

Trước khi đi chi tiết vào đổi mới đào tạo kế toán của hai quốc gia Trung Quốc và Ukraina, bài báo trình tóm tắt xu hướng đào tạo kế toán trên toàn cầu, dẫn tới áp lực đổi mới tại từng quốc gia.

\section{Xu hướng đào tạo kế toán trên toàn cầu}

Theo báo cáo của Karreman và cộng sự (2007), nghiên cứu về xu hướng đào tạo kế toán toàn cầu, dựa trên các xem xét các phát triển chung của kế toán và khảo sát ý kiến với sự tham gia trả lời từ 32 tổ chức nghề nghiệp tại 25 quốc gia trong vòng 5 năm như sau:

Đấy mạn đổi mới giáo duc. Báo cáo cho thấy sự tăng tốc để thay đổi trong giáo dục kế toán. Sự thay đổi chủ yếu bao gồm các hướng dẫn về chuẩn mực đào tạo, sự ra đời của một chế độ tuân thủ, mức độ chấp nhận được của các quy định mới, và có lẽ quan trọng nhất là hợp tác học thuật chuyên nghiệp. Ngày càng gia tăng các hiệp hội nghề nghiệp như Hiệp hội kế toán Mỹ (AAA) và Hiệp hội kế toán châu Âu (EAA) hoạt động trên một khu vực hoặc thậm chí quy mô toàn cầu. Điều này được phản ánh trong báo cáo nhiệm vụ của họ và trong liên kết học thuật chuyên nghiệp. Ngoài ra, còn có các hiệp hội nghề nghiệp khu vực như Hiệp hội kế toán Châu Á (AFA), Hiệp hội kế toán Châu Á Thái Bình Dương (CAPA), ...và các tổ chức nghề nghiệp như Hiệp hội kế toán công chức Anh Quốc (ACCA), Hiệp hội kế toán viên công chứng của Mỹ (AICPA), Hiệp hội kế toán viên hành nghề Úc (CPA Úc) ...

Toàn cầu hóa và hội tụ. Toàn cầu hóa như động cơ và hội tụ như kết quả là những vấn đề lớn đối với sự phát triển liên tục của giáo dục kế toán. Việc chuyển từ hướng dẫn giáo dục quốc tế thành các chuẩn mực giáo dục quốc tế (IES), với vai trò dẫn đầu của IFAC, tạo nên tiêu chuẩn toàn cầu sẵn có, có thể được sử dụng để xác định các khoảng cách hiện tại của mỗi quốc gia. Một trong những kết quả của sự hợp tác quốc tế là sự gia tăng trong việc công nhận lẫn nhau về các trình độ của kể toán viên và kiểm toán viên.

Sự phát triển của quốc gia. Các tổ chức nghề nghiệp được phân biệt theo đặc điểm của quốc gia (hệ thống pháp luật, phát triển kinh tế). Khi các quốc gia có các đặc điểm khác nhau, các tổ chức nghề nghiệp tạo ra các kết nối quốc tế. Điều này được thể hiện bằng việc công nhận lẫn nhau (mở rộng) các bằng cấp.

Tiêu chuẩn chất luợng. Hầu như tất cả các tổ chức nghề nghiệp trong nghiên cứu này đã thay đổi hoặc đang thay đổi tiêu chuẩn chất lượng của họ. Trình độ chuyên môn và cấp giấy phép hành nghề được yêu cầu cho kiểm toán viên, ngay cả đối với các kế toán viên hành nghề.

Đào tạo nghề nghiẹpp. Trong sự phát triển chung, hầu như đào tạo nghề nghiệp phù hợp với chuẩn mực giáo dục quốc tế. Gia tăng cơ hội tốt nghiệp các bằng cấp nghề nghiệp cùng lúc với tốt nghiệp đại học.

Kinh nghiệm thực tế. Hầu như tất cả các tổ chức nghề nghiệp tham gia vào việc phát triển các hệ thống phát triển kinh nghiệm thực tế của họ. Yêu cầu được đưa vào phù hợp với các tiêu chuẩn quốc tế. Nội dung là thiết kế lại để phù hợp với năng lực cho kế toán và kiểm toán viên. Sự công nhận và giám sát của người sử dụng lao động cũng như giám sát các người hướng dẫn được quan tâm nhiều hơn.

Báo cáo xác định các động lực toàn cầu dẫn đến sự thay đổi trong đào tạo kế toán toàn cầu như sau:

- Áp lực cạnh tranh không ngừng

- Tác động của thông tin và công nghệ

- Toàn cầu hóa kinh doanh

- Tập trung vào kế toán giá trị hợp lý 
- Nhu cầu về kiến thức và kỹ năng mới

- Nhu cầu cải tiến trong quản trị doanh nghiệp và đạo đức.

Phạm vi thay đổi trong đào tạo kế toán như sau:

- Đưa ra bài tập tình huống trong việc đánh giá cuối cùng

- Kinh nghiệm thực tế

- Tích hợp giao nhiệm vụ và kiểm tra đánh giá

- Kiểm tra kỹ năng mềm

- Vấn đề đạo đức

- Năng lực dựa trên đánh giá theo điểm

- Các tiêu chuẩn năng lực

\section{Đổi mới đào tạo kế toán trên thế giới. Tình huống cụ thể ở hai nước: Trung Quốc và Ukraina}

\section{Trung Quốc}

Theo ICAS (2010), tháng 2/2006, Bộ tài chính Trung Quốc công bố cho ra đời 39 chuẩn mực kế toán Trung Quốc mới. Mặc dù không áp dụng toàn bộ chuẩn mực lập báo cáo tài chính quốc tế (IFRS) nhưng chuẩn mực mới đã áp dụng các nguyên tắc có trong IFRS và được coi là hội tụ đáng kể với IFRS. Hơn nữa, vào tháng 12/2008, Ủy ban chứng khoán Châu Âu đã cho phép các tổ chức niêm yết Trung Quốc sử dụng chuẩn mực kế toán Trung Quốc ở cộng đồng Châu Âu cho giai đoạn chuyển đổi lên đến 3 năm. Quyết định về sự tương đồng chuẩn mực kế toán Trung Quốc và IFRS sẽ được thực hiện tiếp sau đó.

Chuẩn mực kế toán Trung Quốc mới được áp dụng cho tất cả các công ty niêm yết từ $01 / 01 / 2007$ và áp dụng theo từng giai đoạn cho các doanh nghiệp khác. Và bộ chuẩn mực này sẽ được cập nhật theo sự phát triển của IFRS.

Việc chuyển đổi chuẩn mực kế toán Trung Quốc được cho là thành tựu đáng chú ý. Vì đây là sự thay đổi lớn chuẩn mực kế toán mới tiếp cận theo nguyên tắc so với chuẩn mực kế toán cũ chỉ đi sâu vào chi tiết và theo cơ sở quy định.

Mức độ hỗ trợ của chính phủ Trung Quốc và sự quyết tâm của tất cả các bên liên quan để thực hiện chuẩn mực kế toán Trung Quốc theo IFRS là rất ấn tượng. Các trường hợp gặp vấn đề đã được giải quyết nhanh chóng, các hướng dẫn của Bộ Tài Chính được đánh giá là hữu ích và đơn giản hóa so với chế độ kế toán trước đây.

Theo ICAS (2010), việc đầu tiên đáng lo ngại cần giải quyết là việc các kế toán viên có đủ khả năng để đưa ra các xét đoán dựa vào việc áp dụng các nguyên tắc. Ở Trung Quốc, nơi các kế toán đã quen với việc làm theo nguyên tắc cả về nghiệp vụ và cuộc sống hàng ngày. Thực tế nhiều người làm kế toán được phỏng vấn đã nói rằng "các kế toán ở Trung Quốc không có kinh nghiệm, kiến thức và văn hóa để hiểu cách đưa ra các phán xét". Nền văn hóa Trung Quốc có khuynh hướng không ưa rủi ro, ưu tiên tuân thủ theo các quy tắc luật lệ và lo sợ các bản án từ luật pháp. Chất lượng kế toán viên ở Trung Quốc được đánh giá cao, với những cá nhân có khát vọng về kiến thức và cam kết cải thiện bản thân, học tập suốt đời. Tuy nhiên, cũng có một bộ phận kế toán cũ chỉ quen áp dụng các quy tắc trong hệ thống kế toán cũ.

Theo ICAS (2010), về việc đào tạo kế toán để đáp ứng với yêu cầu vận dụng chuẩn mực mới, Trung Quốc đã thực hiện rất nhiều nỗ lực đáng kể. Kể từ khi có hiệu lực vào tháng 7/2006, Bộ tài chính đã thực hiện chương trình đào tạo rộng khắp với hàng trăm ngàn học viên đã tham gia. Các buổi tập huấn này hướng đến các công ty niêm yết, các doanh nghiệp kế toán, các nhà quản lý luật pháp và cộng đồng học thuật. Các nỗ lực đào tạo được hỗ trợ bởi 3 viện kế toán quốc gia tại Bắc Kinh, Thượng Hải và Hạ Mồn cùng với Hiệp hội kiểm toán viên hành nghề Trung Quốc và Uy ban chứng khoán Trung Quốc. Đồng thời, chú trọng phát triển hệ thống kiểm tra cho kế toán. Bên cạnh đó, Bộ tài chính cũng xây dựng cơ sở hạ tầng, hỗ trợ cơ chế phản hồi việc thực hiện chuẩn mực mới.

Đối với đổi mới đào tạo kế toán ở Trung Quốc, theo Chen (2015), Trung Quốc đã và đang đổi mới việc đào tạo kế toán theo sáng kiến của Ủy ban thay đổi giáo dục kế toán (AECC). Tuy nhiên, nỗ lực này không hoàn toàn ảnh hưởng đến giáo dục kế toán. Đất nước này bận rộn hơn với sự phát triển nghề nghiệp kế toán, hiệp hội nghề nghiệp hơn là giải quyết các vấn đề về chương trình đào tạo để phát triển kỹ năng cho sinh viên.

Theo Hội nghề nghiệp Kế toán Scotland [8], việc cải cách kế toán của Trung Quốc theo hướng dựa vào các nguyên tắc và hội tụ với chuẩn mực kế toán quốc tế. C̣n theo Shiye Yuan (2015), đào tạo kế toán 
tại các trường cao đẳng nghề, nơi đào tạo ra các kế toán viên chuyên nghiệp ở Trung Quốc còn gặp nhiều vấn đề cần giải quyết và khắc phục như: chương trình đào tạo còn tập trung quá nhiều vào lý thuyết, còn thiếu phát triển kỹ năng cho sinh viên, sinh viên thụ động, không có khả năng tự tư duy, phương pháp giảng dạy của giảng viên vẫn thiên về lý thuyết hơn thực hành, chưa tập trung rèn luyện kỹ năng cho sinh viên.

\section{Ukraina}

Theo Mc Gee và cộng sự (2005), Ukraina bắt đầu áp dụng chuẩn mực kế toán trong nước theo chuẩn mực kế toán quốc tế (IAS) vào năm 1999. Chuẩn mực kế toán quốc tế đã được dịch sang tiếng Ukraina nhưng một số hướng dẫn bị cắt bỏ, điều này dẫn tới một vài vấn đề phát sinh. Quá trình chuyển đổi đã thực hiện thành công mặc dù mức độ thành công thì chưa được đồng ý bởi người được phỏng vấn. Theo ý kiến của các nhà hành nghề hiểu biết về IFRS, chuẩn mực kế toán của Ukraina đã giống $80 \%$ IFRS và quy định thuế thì $98 \%$ đã tuân thủ theo IFRS. Gần 700 doanh nghiệp ở Ukraina chuyển đổi sổ sách theo IFRS, tất cả 25 ngân hàng hàng đầu đã lập báo cáo tài chính theo IFRS. Tất cả các công ty niêm yết đã trình bày báo cáo tài chính theo mẫu của IFRS để nộp cho sở chứng khoán. Tuy nhiên, quá trình chuyển đổi vẫn đang tiếp tục và phát sinh nhiều hạn chế như:

- Còn thiếu những người đã được đào tạo trong quá trình chuyển đổi kế toán theo IFRS. Những người trẻ vẫn còn thiếu những người đã được đào tạo bài bản và những người thuộc thế hệ trước không đủ để làm quen với IFRS.

- Phần lớn kế toán ở Ukraina không theo nguyên tắc lập báo cáo tài chính của quốc gia mà thay vào đó họ theo các quy định về thuế. Rất nhiều kế toán viên không cần đến báo cáo tài chính.

- Có những doanh nghiệp lập hai hệ thông báo cáo, một theo IFRS, một theo US GAAP; hoặc họ lập báo cáo tài chính theo IFRS chỉ là để mang tính chất tượng trưng, thống kê.

- Cộng đồng kế toán chưa thực sự quen thuộc với IFRS.

Về đào tạo kể toán, hầu như các trường đại học ở Ukraina đều có một khoa kế toán. Các trường đã bắt đầu kết hợp IFRS và chuẩn mực kiểm toán quốc tế (ISA) vào chương trình giảng dạy kế toán. Tuy nhiên, họ gặp phải một vài vấn đề. Vấn đề đầu tiên, họ thiếu tài liệu giảng dạy tốt. Tài liệu bản ngữ chưa có sẵn trong giai đoạn đầu. Điều này có thể vượt qua bằng cách các giảng viên trong nước viết sách theo tiếng bản ngữ. Những sách này không xuất hiện ở giai đoạn đầu của quá trình chuyển đổi, tuy nhiên ở giai đoạn sau, sách dạng này khá nhiều. Vấn đề tiếp theo là một số sách bị lỗi thời, không cập nhật kịp bởi vì sự thay đổi nhanh chóng của chuẩn mực kế toán Ukraina và áp dụng theo IFRS. Các trường đại học giải quyết vấn đề này bằng cách giao sinh viên đọc thêm các tạp chí kế toán và báo chuyên ngành là tài liệu phụ trợ.

Một vài giảng viên bị phàn nàn rằng quá lý thuyết và không đủ thực tế. Vấn đề này đang ngày càng nan giải khi giảng viên không có kinh nghiệm thực tế nào. Nó sẽ được giải quyết bằng cách thuê giảng viên là những người hành nghề nhiều kinh nghiệm và cho phép giảng viên toàn thời gian làm các công việc kế toán thực tế ngoài trường đại học.

Hàng năm, có sáu mươi hoặc bảy mươi trường đại học ở Ukraina tham gia vào cuộc thi Olympic Kế toán. Nó bao gồm các hội thảo để sinh viên trình bày các bài nghiên cứu của mình. Thỉnh thoảng có sự thi đua giữa các đội. Sự kiện này tăng tính cạnh tranh, tạo kết nối tình bạn giữa sinh viên và cải thiện cái nhìn của sinh viên về kế toán.

Mỗi trường đại học có cách tiếp cận riêng về đào tạo kế toán. Tuy nhiên, chỉ có một vài cách để đổi mới chương trình đào tạo hoặc cách để dạy kế toán. Ví dụ, trường đại học Kinh tế Odessa đào tạo bằng cử nhân 4 năm và bằng thạc sỹ 5 năm. Ngoài ra, chương trình đào tạo đã có những thay đổi quan trọng bởi vì những thay đổi chuẩn mực kế toán trong nước và việc áp dụng IFRS. Trước đây, các trường đại học chỉ có một môn học lý thuyết kế toán và các môn học chuyên ngành như kế toán nông nghiệp. Hiện tại, họ đưa ra đầy đủ các môn học, bao gồm kế toán tài chính, lập báo cáo tài chính, kế toán quản trị, kế toán doanh nghiệp quốc tế và kế toán nước ngoài, kế toán thuế và báo cáo thuế.

Trong chương trình có môn học đặc biệt trong năm 4 yêu cầu sinh viên làm việc với các chứng từ kế toán trong 3 tuần. Các chứng từ được mô phỏng như chứng từ tồn tại trong phòng kế toán thực, từ chứng từ gốc đến các bước khác của quy trình kế toán. Sinh viên phải làm việc với tất cả các vị trí kế toán. 
Trong năm thứ 5 , sinh viên được huấn luyện thực tế. Họ được làm việc với chứng từ thực tế từ công ty có thật. Mỗi sinh viên làm ở một vị trí kế toán với một vài chứng từ. Kết quả cuối cùng là báo cáo tài chính. Công việc bao gồm nhiều chứng từ hơn và nhiều nghiệp vụ hơn tình huống trong năm 4 . Sinh viên cũng phải làm báo cáo thuế dựa trên công việc của họ.

Mô hình học tập là sự kết hợp giữa thuyết giảng, thảo luận và các tình huống. Sinh viên học sử dụng phần mềm máy tính và đây là môn học đặc biệt trên phần mềm máy tính. Tất cả các bài kiểm tra là viết và thường đưa ra ở dạng các bài tập thực hành. Một số bài kiểm tra sinh viên phải lập được báo cáo tài chính.

Khoa kế toán không phải chuyên môn hóa như các nước khác. Phần lớn các giảng viên trường đại học Kinh tế Odessa có thể giảng dạy bất kỳ môn học nào, chứ không phải chỉ dạy kế toán tài chính, kế toán quản trị hoặc kiểm toán. Lợi ích của cách tiếp cận này là buộc giảng viên phải cập nhật theo sự phát triển của tất cả các lĩnh vực trong kế toán.

Ngoài ra, lo sợ bằng cấp kế toán chỉ được công nhận tại Ukraina nên có một số kế toán viên, kiểm toán viên hành nghề đã thi các chứng chỉ quốc tế như Kế toán công chứng Anh Quốc (ACCA), CPA Úc...để được công nhận trên toàn thế giới.

Đối với việc tập huấn cho những kế toán viên, kiểm toán viên đang hành nghề, được thực hiện chủ yếu bởi các công ty kiểm toán lớn Big Four. Bởi vì, Big Four có đầy đủ lực lượng chuyên gia, tài liệu để thực hiện các buổi tập huấn này.

Qua việc nghiên cứu sự triển khai và áp dụng IFRS của Trung Quốc và Ukraina, cho thấy được những thuận lợi và khó khăn của việc triển khai và áp dụng IFRS tại các quốc gia này. Đây là những kinh nghiệm quý báu để giúp Việt Nam rút ra bài học, thực hiện công tác đổi mới đào tạo kế toán sao cho phù hợp.

\section{TÓM LƯợC QUÁ TRÌNH VỀ SỰ PHÁT TRIỂN KẾ TOÁN VÀ ĐÀO TẠO KẾ TOÁN CỦA VIẸT NAM}

Kế toán Việt Nam ra đời từ rất lâu, tuy nhiên xét thời gian từ lúc nước ta giành độc lập thì hệ thống kế toán Việt Nam cũng ra đời kể từ năm 1945. Cùng với quá trình phát triển và cải cách kinh tế, hệ thống kế toán cũng được cải cách theo. Thông qua việc phân tích quá trình cải cách hệ̉ thống kế toán gắn liền với từng giai đoạn cải cách kinh tế, cho thấy việc cải cách kế toán ở nước ta gẳn liền với quá trình cải cách kinh tế. Kế toán ở Việt Nam là công cụ quan trọng trong việc quản lý kinh tế vĩ mô của nhà nước qua từng giai đoạn phát triển kinh tế.

Tính đến nay, hệ thống kế toán Việt Nam đã trải qua khá nhiều giai đoạn lịch sử. Từ hệ thống kế toán chủ yếu tuân thủ các quy định chung của Bộ Tài Chính, kế toán Việt Nam đã chuyển mình phát triển, đổi mới để phù hợp với nền kinh tế thị trường theo định hướng xã hội chủ nghĩa. Chuẩn mực kế toán và kiểm toán hiện nay đã được biên soạn theo chuẩn mực kế toán quốc tế, tuy nhiên việc biên soạn này dựa trên phiên bản cũ của chuẩn mực kế toán quốc tế vì thế nó đã lỗi thời.

Theo Ung Bửu và các Cộng sự (1992), Tadung Huynh et al (2012), quá trình cải cách kế toán của việt nam được chia thành 3 giai đoạn: giai đoạn 1 từ năm 1954 đến năm 1986; giai đoạn 2 từ 1986 đến 1995; giai đoạn 3 từ 1995-2001; gia đoạn 4 từ 2002-đến nay.

- Giai đoạn 1 từ năm 1954 đến năm 1986

Nền kinh tế nước ta vận hành theo cơ chế kế hoạch hoá tập trung. Kế toán trong thời kỳ này được sử dụng như một công cụ để phản ánh và giám đốc các hoạt động sản xuất kinh doanh và sử dụng vốn nhà nước.

- Giai đoạn từ 1986 đến 1995:

Nước ta chuyển đổi nền kinh tế từ nền kinh tế bao cấp sang nền kinh tế thị trường định hướng xã hội chủ nghĩa. Đây là giai đoạn đầu tiên tiến hành đổi mới công tác kế toán để phục vụ cho yêu cầu xoá bỏ cơ chế tập trung quan liêu bao cấp, xây dựng cơ chế mới về quản lí kinh tế nhằm phát huy tính chủ động sáng tạo của các cơ sở kinh doanh. 
- Giai đoạn từ 1995 đến 2000

Đặc điểm nổi bật nhất của giai đoạn này là sự chuyển hướng từ nền kinh tế kế hoạch sang nền kinh tế thị trường theo định hướng xã hội chủ nghĩa. Chủ trương của nhà nước là thu hút vốn đầu tư của nước ngoài, các doanh nghiệp nhà nước phải hoạt động trong môi trường cạnh tranh, tuân thủ luật pháp. Với sự chuyển mình của nền kinh tế nước ta, sự ra đời của hệ thống kế toán mới, một hệ thống kế toán bước đầu đã hội nhập vào những thông lệ chung của kế toán thế giới, tạo điều kiện thu hút đầu tư, thúc đẩy sản xuất phát triển, giúp Việt Nam sớm hoà nhập vào kinh tế khu vực và thế giới.

- Giai đoạn 2001 đến nay

Trong giai đoạn này, nền kinh tế nước ta đã hội nhập vào nền kinh tế khu vực và thế giới. Cùng với sự phát triển kinh tế, kế toán cũng có sự phát triển vượt bậc trong giai đoạn này và được đánh dấu bởi sự ra đời của Luật kế toán Việt Nam do quốc hội khoá XI kỳ họp thứ 3 thông qua cũng như các chuẩn mực về kế toán tài chính riêng của Việt Nam đã được ban hành. Kế toán tài chính tại Việt Nam không còn phát triển một cách đơn lẻ tự phát nội bộ mà đã có hệ thống và liên kết với thế giới. Đánh dấu bước phát triển quan trọng này là vào năm 1996 Hội kế toán Việt Nam (VAA) ra đời và trở thành thành viên của Liên đoàn kế toán quốc tế (IFAC) cũng như là thành viên của Liên đoàn kế toán các nước ASEAN (AFA).

Hiện nay hệ thống kế toán của nước ta đã được cải tiến sâu, rộng để hội nhập với khu vực và thế giới. Bộ Tài Chính cũng đã có lộ trình rõ ràng về hội nhập kế toán Quốc tế bằng cách vận dụng IFRS theo một lộ trình nhất định như đã trình bày ở trên. Cùng với sự phát triển của hệ thống kế toán, đào tạo kế toán Việt Nam cũng phát triển nhanh để đáp ứng yêu cầu của xã hội, cung cấp được nguồn nhân lực kế toán, kiểm toán đủ kiến thức và kỹ năng cần thiết. Tuy nhiên, theo PGS. TS. Nguyễn Xuân Hưng (2017), đào tạo kế toán Việt Nam theo hướng hội nhập IFRS vẫn còn gặp nhiều khó khăn nhu:

- Mặc dù một số trường đại học đã đưa IAS/IFRS vào giảng dạy ở bậc cử nhân, tuy nhiên do khung pháp lý kế toán Việt Nam vẫn chú trọng nhiều vào các quy định cụ thể trong khi IAS/IFRS theo khuynh hướng kế toán dựa trên nguyên tắc nên các trường đại học vẫn phải giảng dạy theo tinh thần hướng dẫn các quy định cụ thể để sinh viên có thể đáp ứng được yêu cầu thực tiễn trong công việc.

- Cơ chế chính sách còn chưa hoàn thiện, do vậy một số kỹ thuật đặc biệt của IFRS còn chưa có căn cứ pháp lý để thực hiện, ví dụ việc ghi nhận tổn thất tài sản, việc ghi nhận giá trị hợp lý của một số tài sản tài chính, bất động sản đầu tư hoặc tài sản sinh học đều chưa được hướng dẫn. Cho dù IAS/IFRS có đưa vào giảng dạy, nhưng do môi trường pháp lý chưa hoàn thiện nên người dạy sẽ gặp khó khăn trong quá trình giải thích các nguyên tắc của chuẩn mực IAS/IFRS sẽ áp dụng như thế nào tại Việt Nam, cũng như người học chưa thấy được sự hữu ích khi học về IAS/IFRS nên thái độ tiếp thu còn thờ o, học theo kiểu đối phó.

- Hiểu biết và kinh nghiệm của các giảng viên Việt Nam về IAS/IFRS vẫn còn rất hạn chế, đây được coi là một trong những thách thức lớn. Cho đến nay, việc hiểu biết và vận dụng chuẩn mực kế toán Việt Nam vẫn còn nhiều bất cập, chưa nói đến về kiến thức và kinh nghiệm về IAS/IFRS.

- Thiếu cơ chế hợp tác chặt chẽ giữa cơ sở đào tạo và doanh nghiệp. Vì thế, các giảng viên khó tiếp cận với thực tiễn để hiểu rõ các nguyên tắc của IAS/IFRS được vận dụng như thế nào tại Việt Nam, cần có những điều chỉnh hợp lý nào. Từ kiến thức thực tiễn, giảng viên sẽ mang vào nội dung bài giảng để nó phong phú và có tính thực tế cao.

- IAS/IFRS thường xuyên cập nhật, thay đổi, kéo theo các giảng viên phải liên tục cập nhật kiến thức và bài giảng cho phù hợp với sự thay đổi của IAS/IFRS.

- Khó khăn về rào cản ngôn ngữ. IAS/IFRS được biên soạn bằng tiếng Anh trong khi đó khả năng đọc, hiểu bằng ngôn ngữ này của sinh viên và giảng viên Việt Nam còn hết sức hạn chế.

- Chi phí tài liệu để học, nghiên cứu IAS/IFRS còn khá tốn kém đối với điều kiện kinh tế của sinh viên Việt Nam nếu sinh viên phải sử dụng tài liệu bản quyền từ tổ chức biên soạn chuẩn mực IAS/IFRS.

Từ những khó khăn này, Việt Nam rất cần học hỏi các kinh nghiệm đổi mới đào tạo kế toán ở các nước đi trước, nhằm giảm bớt thời gian, công sức và chi phí. Thông qua việc nghiên cứu ở trên, bài báo trình bày những bài học kinh nghiệm rút ra cho Việt Nam trong việc đổi mới đào tạo kế toán theo hướng tiếp cận IFRS. 


\section{BÀI HỌC KINH NGHIỆM CHO VIỆT NAM}

Từ việc nghiên cứu sự đổi mới đào tạo kế toán của hai quốc gia Ukraina và Trung Quốc, nhóm tác giả phân tích, so sánh với sự phát triển, cải cách kế toán của Việt Nam qua đó rút ra một số bài học có ý nghĩa thực tiễn cho Việt Nam trong việc đổi mới đào tạo kế toán theo hướng áp dụng IFRS:

Thư nhất là, xác định rõ việc đổi mới kế toán ở nước ta theo hướng hội tụ kế toán Quốc tế và sử dụng IFRS trong việc lập và trình bày báo cáo tài chính. Từ đó xác định rõ mục tiêu đào tạo kế toán của các tổ chức đào tạo hiện nay là đào tạo theo hướng tiếp cận các nguyên tắc, các lý luận kế toán.

Thư hai là, về chương trình đào tạo, các trường đại học và các tổ chức đào tạo cần tập trung xây dựng chương trình đào tạo cho phù hợp, cân đối các môn học chuyên ngành phù hợp để đảm bảo sinh viên ra trường đủ chất lượng để đảm nhận các công việc kế toán, kiểm toán khi Việt Nam đã áp dụng IFRS. Rút kinh nghiệm Trung Quốc trong việc xây dựng chương trình đào tạo còn mang nhiều lý thuyết, ít thực hành theo Shiye Yuan (2015), do đó trong chương trình đào tạo, cần gia tăng thời gian của các môn thực hành, vận dụng IFRS để lập báo cáo tài chính. Giảng dạy cho sinh viên làm quen với việc áp dụng các xét đoán dựa trên các nguyên tắc, không hướng dẫn quá chi tiết và tuân thủ theo luật lệ như trước đây và hiện nay.

Thứ ba là, về tài liệu học tập, các trường đại học và các tổ chức đào tạo cần lựa chọn tài liệu giảng dạy phù hợp. Ví dụ, Ukraina chọn tài liệu giảng dạy do các giáo sư, giảng viên biên soạn và kèm các tài liệu phụ trợ như các bài báo, tạp chí chuyên ngành... Bên cạnh đó, các tài liệu này phải được dịch ra tiếng Việt nhằm hỗ trợ người học hiểu rõ nội dung IFRS.

Thư tu là, về đội ngũ giảng viên giảng dạy, cần tiến hành mở các lớp đào tạo miễn phí cho các giảng viên hiểu rõ về IFRS, thường xuyên tổ chức tập huấn để cập nhật nội dung mới của IFRS. Hơn nữa, có thể gửi một số sinh viên, giảng viên ra nước ngoài để được đào tạo. Với mục đích tránh trường hợp giảng viên không có thực tế, dạy lý thuyết suông, cần tạo điều kiện cho các giảng viên được làm các công việc kế toán, kiểm toán thực tế, đồng thời để tăng tính thực tế của chương trình đào tạo, nhà trường có thể mời thêm các chuyên gia, các kế toán viên, kiểm toán viển hành nghề có kinh nghiệm về giảng dạy.

Thư năm là, về việc đào tạo cho đội ngũ kế toán, kiểm toán viên đang hành nghề, đội ngũ này hết sức quan trọng vì họ sẽ áp dụng các quy định mới của Bộ Tài Chính, Hội kế toán và kiểm toán Việt Nam (VAA), hội kiểm toán viên hành nghề Việt Nam (VACPA) cần tham gia tích cực và chủ đạo vào hoạt động đào tạo, tập huấn này. Bên cạnh đó, cần quan tâm đến việc đào tạo, cập nhật cho các đối tượng liên quan khác như các cơ quan kiểm tra thuế, các nhà quản lý.

Thư sáu là, về công tác chuyển đổi từ hệ thống kế toán cũ sang hệ thống kế toán mới, cần xây dựng một đội ngũ chuyên tư vấn, hướng dẫn, đào tạo hỗ trợ các doanh nghiệp, kế toán viên trong quá trình chuyển đồi.

\section{KẾT LUẬn}

Bộ Tài Chính Việt Nam đang định hướng lộ trình áp dụng IFRS vào Việt Nam khá rõ ràng. Việc áp dụng IFRS vào Việt Nam chỉ là sớm hay muộn, không còn là có hay không nữa. Vì vậy, các bên liên quan cần chung tay tích cực vào cuộc để hỗ trợ Bộ Tài Chính trong quá trình đưa IFRS về Việt Nam. Trong đó, phải kể đến các nhà đào tạo kế toán gồm các trường đại học và các tổ chức đào tạo. Họ phải chủ động đổi mới đào tạo kế toán, nhằm nâng cao chất lượng đào tạo, cho ra đời thế hệ sinh viên, học viên có đủ năng lực, trình độ, kỹ năng vận dụng IFRS trong công tác kế toán, kiểm toán tại doanh nghiệp. Với bài báo này, nhóm tác giả mong muốn góp một phần nhỏ, một góc nh́n thông qua các kinh nghiệm đổi mới đào tạo ở các nước trên thế giới, từ đó rút ra một số bài học kinh nghiệm hữu ích, quý báu cho Việt Nam trong quá trình triển khai, đào tạo và áp dụng IFRS thành công.

Hạn chế của nghiên cứu là chỉ mới khảo sát được việc đổi mới đào tạo của hai quốc gia là Trung Quốc và Ukraina, trên thực tế việc đổi mới đào tạo này đã và đang diễn ra ở rất nhiều nước trên thế giới. Ở các nghiên cứu tiếp theo, nhóm tác giả sẽ mở rộng khảo sát nhiều quốc gia hơn nữa để có nhiều bài học kinh nghiệm cho Việt Nam.

\section{LÒ̀I CẢM ƠN}

Chúng tôi muốn gửi lời cảm ơn tới các đồng nghiệp và những người cộng tác. Chúng tôi cảm ơn đến tất cả các tác giả mà chúng tôi trích dẫn trong bài báo. 


\section{TÀI LIÊU THAM KHẢO}

[1] Chen, Theodore T. Y., 2015. Is Reform in Accounting Education Needed in China and Russia: A Literature Review, Australasian Accounting, Business and Finance Journal, 9(3), doi: $\underline{10.14453 / a a b f j . v 9 i 3.6}$

[2] Tandung Huynh, Doan Van Dinh, Guangming Gong, 2012. Vietnamese Accounting System Reform Review and Prospect. Australian Journal of Basic and Applied Sciences, 6(9).

[3] ICAS, 2010. The Institute of Chartered Accountants of Scotland, Chinese Accounting Reform: Towards a principles - based global regime. Available at https://www.icas.com/technical-resources/chinese-accounting-reform

[4] Karreman, G. H., Ahern Jr. J. T., Kuijl, J. G. and Marrian, I. F. Y., 2007. GAE 2007 Trends in Global Accounting Education, In Royal Nivra, Amsterdam,

[5] McGee, Robert W, 2003. Reforming Accounting Education in a Transition Economy: A Case Study of Armenia. International Management Development Association, Forthcoming. Available at SSRN https://ssrn.com/abstract=408980 or http://dx.doi.org/10.2139/ssrn.408980

[6] Mc Gee, Robert W. and Preobragenskaya, Galina, 2005. Accounting Reform in Transition Economies: A Case Study of Ukraine. Available at SSRN

https://ssrn.com/abstract=686430 or http://dx.doi.org/10.2139/ssrn.686430

[7] Nguyễn Xuân Hưng, 2017, Định hướng đào tạo Kế toán tại Việt Nam trong quá trình hội nhập chuẩn mực lập báo cáo tài chính Quốc tế (IFRS), Hội thảo khoa học “Đổi mới phương pháp đào tạo, cập nhật giáo trình giảng dạy kế toán phù hợp với yêu cầu cải cách kế toán trong giai đoạn mới”, NXB Lao động.

[8] Shiye Yuan, 2015. Study on Reform of Accounting Education Mode of Higher Vocational Schools Based on Training in High-Caliber Professional Accountants, 2nd International Conference on Education Reform and Modern Management. Available at http://www.atlantis-press.com/php/download paper.php?id=20826

[9] The Institute of Chartered Accountants of Scotland, 2010. 'Chinese accounting reform: Towards a principles based globe regime', Available from www.icas.org.uk

[10] Ung Bửu và Cộng sự, 1992. Bài giảng môn lý thuyết kế toán hệ cao học. Trường Đại Học Kinh tế thành phố Hồ Chí Minh.

Ngày nhận bài: 14/08/2017

Ngày chấp nhận đăng: 09/11/2017 